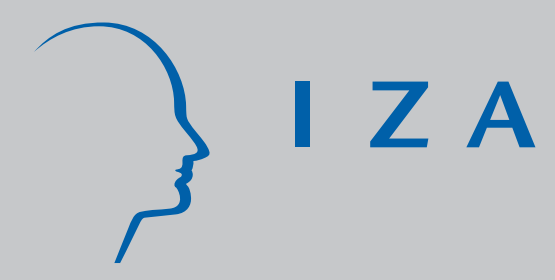

IZA DP No. 1844

Tournaments and Multiple Productive Inputs:

The Case of Performance Enhancing Drugs

Kai A. Konrad

November 2005 


\title{
Tournaments and Multiple Productive Inputs: The Case of Performance Enhancing Drugs
}

\author{
Kai A. Konrad \\ $W Z B$, Free University of Berlin \\ and IZA Bonn \\ Discussion Paper No. 1844 \\ November 2005
}

\author{
IZA \\ P.O. Box 7240 \\ 53072 Bonn \\ Germany \\ Phone: +49-228-3894-0 \\ Fax: +49-228-3894-180 \\ Email: iza@iza.org
}

\begin{abstract}
Any opinions expressed here are those of the author(s) and not those of the institute. Research disseminated by IZA may include views on policy, but the institute itself takes no institutional policy positions.

The Institute for the Study of Labor (IZA) in Bonn is a local and virtual international research center and a place of communication between science, politics and business. IZA is an independent nonprofit company supported by Deutsche Post World Net. The center is associated with the University of Bonn and offers a stimulating research environment through its research networks, research support, and visitors and doctoral programs. IZA engages in (i) original and internationally competitive research in all fields of labor economics, (ii) development of policy concepts, and (iii) dissemination of research results and concepts to the interested public.
\end{abstract}

IZA Discussion Papers often represent preliminary work and are circulated to encourage discussion. Citation of such a paper should account for its provisional character. A revised version may be available directly from the author. 
IZA Discussion Paper No. 1844

November 2005

\section{ABSTRACT}

\section{Tournaments and Multiple Productive Inputs: The Case of Performance Enhancing Drugs}

In this paper I consider the desirability of drugs that enhance cognitive abilities in the context of tournaments that are used as optimal labor contracts as in Lazear and Rosen (1981). Such drugs reduce the number of voluntary participants in a tournament, but increase individual and total output. If the tournament is optimally designed, welfare is higher if drugs are available and used.

JEL Classification: D72, D74, L23, M54

Keywords: cognitive enhancement drugs, tournament, labor market incentives, doping, entry in tournaments

Corresponding author:

Kai A. Konrad

WZB

Reichpietschufer 50

10785 Berlin

Germany

Email: kkonrad@wz-berlin.de 


\section{Introduction}

Technological progress may soon lead to developed markets for drugs that could be used by perfectly healthy people to temporarily and selectively enhance specific cognitive abilities. Robbins, Metha and Sahakian (2000, p. 2276) for example, describe and survey results that "...raise the exciting possibility that aspects of working memory may be improved by drugs with selective actions on different neurotransmitter systems, resulting in possible therapeutic benefits for patients with cognitive disorders such as Alzheimer's diseases." A recent article by Butcher (2003) reports that such drugs that have initially been developed to cure mind-degenerative diseases (Alzheimer's), can be, and are, frequently used by healthy young people to improve their cognitive performance and their ability to memorize knowledge. Methylphenidate, for instance, is reported to enhance a person's ability to focus and study. Once the mechanisms explaining the functioning of the human brain are fully discovered, it is only a small step to develop drugs that can be used to stimulate or enhance specific cognitive abilities.

Such means have implications for regulation. One issue is consumer information and potential externalities to society that have been discussed in relation with drug consumption more generally (for a balanced discussion and a survey, see Miron and Zwiebel 1995). In this paper I consider a full information framework in which most of these issues play no role or can be efficiently solved. Instead, I concentrate on the implications of tournament externalities from a contestant's performance enhancement. A tournament is typically characterized by a group of competitors who may spend effort to produce some observable performance or output, a function that turns these outputs into individual probabilities of winning the tournament, and rules about what kinds of effort that increase a participant's own output are, or are not, legitimate. A participant's effort in a tournament improves his own position, but makes the position of others worse. Hence, output generating effort has a negative externality. Performance enhancement will generally change competitors' effort, and may change the size and scope of externalities in the tournament. For this reason it could be important to discuss the implications for efficiency and distribution in tournaments of the availability of drugs that enhance cognitive abilities, and to address the question of whether their use should be controlled or restricted. ${ }^{1}$

\footnotetext{
${ }^{1}$ The discussion of doping has some tradition in the economics of sports. There, a general consensus makes researchers start with the presumption that doping should be
} 
Existing substances and other instruments may have been used to increase individual abilities that are desirable in situations that are appropriately described as tournaments. However, their effectiveness with respect to the intended influence on mental abilities has been rather limited so far, and their side effects were considerable, making their use not very attractive. Medical progress may now lead to a new quality of "brain doping" in many types of contexts, for instance, in research and development tournaments between academics, or in the workplace, when tournaments are used as incentive instruments. Butcher (2003) associates such activities with doping in sports and suggests a debate on whether the use of such neurotechnologies should be controlled, particularly in tournament environments. He reports a number of concerns, particularly from ethicists about the use and abuse of such technologies. ${ }^{2}$

I will consider just one of the various dimensions of such a debate and ask how the availability of a particular (new) type of effort affects the tournament outcome and the optimal design of the tournament. I will concentrate on a tournament in which observable output is valuable, and in which the contest designer uses the tournament as an optimal labor contract in order to maximize expected output net of the cost of the prize that he has to give to the contestants. This set-up is relevant in R\&D tournaments, or in tournaments that are used as incentive contracts for workers inside a firm. I extend the standard framework developed by Lazear and Rosen (1981) and Green and Stokey (1983) and surveyed in Lazear (1995) to study the decisions to enter into a tournament and to spend effort in a tournament by considering a technology in which output is generated as a function of several types of productive effort. The literature has addressed sabotage effort that is aimed at diminishing other contestants' observable output, ${ }^{3}$ but the production function that translates various resources of the competitor into observable valuable output, has mainly been treated as a black box. ${ }^{4}$

illegal and makes them consider the optimality of mechanisms to implement a ban on doping. See, for instance, Berentsen (2002), Eber and Thépot (1999) and Maennig (2002).

${ }^{2}$ Consideration of such issues might have induced Eyster and Rabin (2003) to certify in a footnote of their paper that they had not consumed cocaine during the last few decades.

${ }^{3}$ See the seminal work by Lazear (1989) and more recent contributions by Auriol, Friebel and Pechlivanos (2002), Chen (2003) and Kräkel (2000).

${ }^{4}$ The only exception known to me is Epstein and Hefeker (2003) who consider a parametric version of an effort function that exhibits strongly increasing returns in a somewhat different context. They ask whether and when both factors are used by contestants in twoplayer Tullock rent-seeking contests and do not address the issue of regulation. 
Whereas sabotage has been shown to be generally detrimental to the overall efficiency of tournaments in which the competitors produce valuable output, the optimal level of cognitive enhancement effort turns out to be strictly positive and improves overall efficiency, despite the negative externalities that any effort exhibits in a tournament. If the number of participants can be limited from above, overall rents of society are typically higher if ability enhancing drugs are available and used. Also such effort has a number of distributional implications. The availability of such effort will typically decrease an individual's rents from taking part in the tournament if the prize of winning and the number of participants are given. The number of competitors who enter into a tournament if the tournament prize is fixed will be higher if one of the types of effort is not available.

In section 2, I will consider drugs that enhance cognitive abilities in a context in which the organizer designs the contest and aims at maximizing total output. In section 3 , I will ask whether and when availability of certain types of effort could be undesirable in other types of tournaments, particularly in selection tournaments or in sports tournaments. Section 4 concludes.

\section{The tournament}

Let there be $n$ participants in the tournament, where this number can be exogenous or endogenous. Individuals produce some output. For this they use one regular type of effort (e.g., time) and may but need not use some additional type of effort that involves the use of cognitive enhancement drugs. The observed output of contestant $i$ will be denoted $y_{i}$ and will be a function of the efforts and of some noise, as will be explained later. The vector of these $y_{i}$ of active players determines the participants' probabilities $p_{i}\left(y_{1}, \ldots y_{n}\right)$ of winning a prize of size $Z$ that are non-negative and sum up to 1 . I assume that $i$ wins with certainty if

$$
y_{i}>\max _{j \neq i}\left\{y_{j}\right\} .
$$

If there are $k$ participants with the same maximum output, the prize is allocated to each of them with a probability $1 / k$.

The observable output $y_{i}$ in the standard framework is the effort or a monotonic function of it, plus noise $e_{i}$. This is where I depart from the standard framework by assuming that $y_{i}$ is produced by two types of costly 
inputs, plus noise. One of the inputs by contestant $i$ is denoted by $a_{i}$ and can be seen as the regular effort considered in the standard framework, and may impose a cost on the contestant. The cost is denoted $A\left(a_{i}\right)$, with $A(0)=0$, $A^{\prime}\left(a_{i}\right)>0$ and $A^{\prime \prime}\left(a_{i}\right)>0$. There is a second input, denoted $b_{i}$ which is the amount of drug use by contestant $i$. Drug use also generates a cost. For instance, drugs that influence mental performance require some monetary expenditure for the drug itself, plus the monetary equivalent of how the individual evaluates the side effects of consuming these drugs. The cost will be denoted $B\left(b_{i}\right)$, with $B(0)=0, B^{\prime}\left(b_{i}\right)>0$ and $B^{\prime \prime}\left(b_{i}\right)>0 .{ }^{5}$

Observable output is defined along the lines of the 'classic' approach to describe uncertainty in production as a function of the inputs and a random variable. To bring this in line with the standard approach of tournaments, noise enters additively, and this yields observable output as

$$
y_{i}=f\left(a_{i}, b_{i}\right)+e_{i} .
$$

Here, $e_{i}$ for $i=1, \ldots n$ are identically and stochastically independently distributed random variables with density functions $g(e)$ and with the cumulative density functions denoted $G(e)$. The function $f\left(a_{i}, b_{i}\right)$ is a regular production function with two factors of production. Denoting partial derivatives of $f$ with respect to the two inputs by subscripts $a$ and $b$, both factors have positive but decreasing marginal returns and that the factors are (weak) complements, i.e., $f_{a}>0, f_{b}>0, f_{a a}<0, f_{b b}<0$ and $f_{a b} \geq 0 .{ }^{6}$ To make this intuitive, think, for instance, about drugs that increase the ability to memorize or store information, and let the other input be time spent on learning. It seems to be natural that the two factors are complements. A given amount of time spent on learning will generate better results under the influence of drugs that enhance the brain's ability to memorize, and the drug is more useful in generating learning effect if the person spends some (more) time on learning.

Whether drugs are available or not can now be described by an exogenous zero constraint on $b_{i}$ for all $i$. A ban on drugs, or the non-existence of the

\footnotetext{
${ }^{5}$ Additive separability of this cost function is mainly for simplifying the comparison of the unrestricted case and the case with $b \equiv 0$. For a generalization of the results, some restrictions about the interaction of $a$ and $b$ in the cost function would be required.

${ }^{6}$ Uncertainty may also interact in different ways with output, and different inputs may affect uncertainty differently. If, for instance, it is known that the use of input a generates a higher output variance than input $b$, then input choice becomes important for the strategic choice of riskiness of tournaments that leads to interesting aspects that have been analysed by Hvide (2002) and Kräkel and Sliwka (2003).
} 
drugs, implies that $b_{i}=0$, whereas $b_{i}$ is a matter of choice if drug use is unconstrained.

The objective function of individual $i$ who can take part in the tournament is

$$
H_{i} \equiv p_{i}\left(y_{1}, \ldots y_{n}\right) Z-A\left(a_{i}\right)-B\left(b_{i}\right) .
$$

Active participants in the tournament simultaneously and independently choose $\left(a_{i}, b_{i}\right)$ if drug use is unregulated, and $\left(a_{i}, 0\right)$ if drug use is banned. The designer of the tournament, typically a firm if the tournament is used as an incentive scheme inside firms, maximizes the difference between the sum of expected equilibrium outputs and the prize, i.e.,

$$
D \equiv \sum_{i=1}^{n} f\left(a_{i}, b_{i}\right)-Z,
$$

where the contest designer may be able to choose the size of the prize $Z$ and/or the number $n$ of contest participants. Finally, expected aggregate rent or welfare is

$$
W \equiv \sum_{i=1}^{n}\left[f\left(a_{i}, b_{i}\right)-A\left(a_{i}\right)-B\left(b_{i}\right)\right] .
$$

Consider now the contest outcome for an exogenously given number $n$ of participants and for a given prize. Contestants' first-order conditions are

$$
\frac{\partial H_{i}}{\partial a_{i}}=\frac{\partial p_{i}}{\partial y_{i}} f_{a}\left(a_{i}, b_{i}\right) Z-A^{\prime}\left(a_{i}\right)=0
$$

and

$$
\frac{\partial H_{i}}{\partial b_{i}}=\frac{\partial p_{i}}{\partial y_{i}} f_{b}\left(a_{i}, b_{i}\right) Z-B^{\prime}\left(b_{i}\right)=0
$$

for the unconstrained case, and by

$$
\frac{\partial H_{i}}{\partial a_{i}}=\frac{\partial p_{i}}{\partial y_{i}} f_{a}\left(a_{i}, 0\right) Z-A^{\prime}\left(a_{i}\right)=0
$$

if drug use is banned, or of the drug is unavailable for other reasons. Here $\partial p_{i} / \partial y_{i}$ is an abbreviation for the effect of an increase in $f\left(a_{i}, b_{i}\right)$ by one unit on $i$ 's probability to win the tournament. As usual in this literature, I assume that an interior equilibrium exists that is characterized by the first-order conditions. Let $\left(a^{*}, b^{*}\right)$ and $\left(a^{p}, 0\right)$ with ' $p$ ' for prohibition be the solutions of $(6)$ 
and (7) and of (8), respectively. These are the effort levels in the symmetric Nash equilibrium if they are compatible with participation constraints, i.e., if

$$
\frac{Z}{n}-A\left(a^{*}\right)-B\left(b^{*}\right)>0
$$

if the drug is available and

$$
\frac{Z}{n}-A\left(a^{p}\right)-B(0)>0
$$

if the drug is unavailable, where the payoff in the outside option of not taking part in the tournament has been normalized to zero. ${ }^{7}$

Suppose the conditions (9) and (10) are fulfilled. Note that, for $a_{1}=a_{2}=$ $\ldots=a_{n}$ and $b_{1}=b_{2}=\ldots=b_{n}$,

$$
\frac{\partial p_{i}}{\partial y_{i}}=\int_{-\infty}^{+\infty}\left[(n-1) G(e)^{n-2} g(e)^{2}+G(e)^{n-1} g^{\prime}(e)\right] g(e) d e \equiv p^{\prime}(\mathbf{0})
$$

and $p^{\prime}(\mathbf{0})$ is the same for all three equations (6), (7) and (8). Here, $\mathbf{0}$ denotes combinations of effort choices in which all effort differences $a_{i}-a_{j}=0$ and $b_{i}-b_{j}=0$. This yields the following result:

Proposition 1 Let (9) and (10) be non-binding for given $n$. Then $a^{*} \geq a^{p}$ and $f\left(a^{*}, b^{*}\right) \geq f\left(a^{p}, 0\right)$. Moreover, if these inequalities hold strictly, the rents of tournament participants are lower in the unconstrained tournament than if $b_{i}=0$ for all participants $i$ is required.

Proof. In the unconstrained economy, drugs are used if $p^{\prime}(\mathbf{0}) f_{b}\left(a^{p}, 0\right) Z>$ $B^{\prime}(0)$. If drugs are not used in the unconstrained equilibrium, Proposition 1 is trivially fulfilled. If drugs are not used, $a^{p}$ is determined by $p^{\prime}(\mathbf{0}) f_{a}\left(a^{p}, 0\right) Z=$ $A^{\prime}\left(a^{p}\right)$. If drugs are used, $a^{*}$ is determined by $p^{\prime}(\mathbf{0}) f_{a}\left(a^{*}, b^{*}\right) Z=A^{\prime}\left(a^{*}\right)$, where $p^{\prime}(\mathbf{0})$ is the same in both conditions. Hence, $f_{a}\left(a^{p}, b^{*}\right)>f_{a}\left(a^{p}, 0\right)$ for $b^{*}>0$ and convexity of $A(a)$ imply $a^{*}>a^{p}$. The result on the expected output follows from $a^{*} \geq a^{p}$ and $b^{*} \geq 0$. Each tournament participant has a rent in the unrestricted case that is equal to $(Z / n)-A\left(a^{*}\right)-B\left(b^{*}\right)$, and by

\footnotetext{
${ }^{7}$ I will not emphasize these constraints, because a tournament designer can always make them fulfilled by handing out not only a winner prize but also appropriately chosen loser prizes. $Z$ can then be thought of as the chosen difference between the winner prize and the loser prize.
} 
$a^{*}>a^{p}$ and $b^{*} \geq 0$ this is smaller than the equilibrium rent $(Z / n)-A\left(a^{p}\right)$ in the constrained case.

Intuitively, with a second input with low marginal cost at low levels of this input, the individual benefits in terms of increases in output and the improvement in own position, this generates in the tournament outweigh these low costs. As drugs are used by all contestants, they all end up in a situation in which they all generate the same expected output. This is important because it simplifies the implications the change in equilibrium inputs has on the marginal effect of individual increases in expected output on the individual win probability.

Proposition 1 is perhaps key for understanding common concerns about the use of drugs with cognitive enhancement effects. Availability of such drugs in tournaments will change the tournament outcome, and, for a tournament with a given prize and a given number of participants, the availability of a complementary input factor will reduce the rents of each participant. ${ }^{8}$ Accordingly, in this partial context, contestants prefer a ban on such drugs.

Let $n$ now be given but consider changes in $Z$. An increase in $Z$ for given $n$ will make it more likely that the participation constraints (9) and (10) are fulfilled. Also, such an increase will generally cause more output both in the tournament without a zero constraint and in the contest with such a constraint. We can ask what size of prize will generally maximize the total rents. An interesting result on the welfare implications of doping effort in a world in which the output of contest effort is valuable is

Proposition 2 Let $n$ be given and let

$$
\frac{1}{n p^{\prime}(\mathbf{0})} \geq A\left(a^{*}\right)+B\left(b^{*}\right)
$$

(i) The $Z$ that maximizes total rent (5) for this $n$ is

$$
Z=\frac{1}{p^{\prime}(\mathbf{0})} \text {. }
$$

(ii) For the $Z$ that maximizes total rent in the tournament as defined in (5) this rent is not lower if the drug is available.

\footnotetext{
${ }^{8}$ Complementarity of the two input factors is an important assumption for the results in Proposition 1. It implies that $b>0$ increases the productivity of $a$ and yields the increase in $a$, and, hence, the increase in total effort. If the two inputs are mere perfect substitutes, i.e., $f(a, b)=f(a+b)$, total observed output will be higher due to the convexity of $A(a)$ and $B(b)$, but typically $a^{p} \leq a^{*}$ will hold.
} 
Proof. I will first disregard the participation constraints (9) and (10) and turn to them later. Consider claim $(i)$. In the tournament without a zero constraint on $b_{i}$ the measure of total tournament rents is $f\left(a^{*}, b^{*}\right)-$ $A\left(a^{*}\right)-B\left(b^{*}\right)$. This sum is maximal if $a^{*}$ and $b^{*}$ are determined by the conditions $f_{a}=A^{\prime}\left(a^{*}\right)$ and $f_{b}=B^{\prime}\left(b^{*}\right)$. These values of $a^{*}$ and $b^{*}$ can, in turn, be implemented for a given $n$ by a choice of $Z$ such that $Z p^{\prime}(\mathbf{0})=1$, as can be seen from the first-order conditions (6) and (7). Similarly, $Z$ that maximizes total rents if drug use is banned is determined such that $a^{p}$ fulfills $f_{a}\left(a^{p}, 0\right)=A^{\prime}\left(a^{p}\right)$ and this is also the case if $Z p^{\prime}(\mathbf{0})=1$, that is, for the same size of prize. Return now to the participation constraints. For the case without a zero constraint on drug use, the participation constraint is $\frac{Z}{n}-A\left(a^{*}\right)-B\left(b^{*}\right) \geq 0$, or, using the relationship between the optimal $Z$, $p^{\prime}(\mathbf{0})$ and $n, \frac{1}{n p^{\prime}(\mathbf{0})}-A\left(a^{*}\right)-B\left(b^{*}\right) \geq 0$. Note that this constraint is more restrictive than the respective constraint for $b \equiv 0$. Turn now to claim (ii). The convexity of the production technology implies that the rents are not lower with $\left(a^{*}, b^{*}\right)$ than with $\left(a^{p}, 0\right)$.

The first result in proposition 2 shows that the prize that maximizes total rent does not depend on the availability of the second input, provided that its availability does not lead to a violation of the participation constraint. The second result is very straightforward, but has an important policy message. If there is an additional type of effort that could be used in a tournament and enhances own output, this type of effort should not be banned if the tournament is designed to maximize the expected output net of effort cost. Hence, from a normative point of view, the tournament environment as such does not suggest a ban for pharmaceuticals that enhance a worker's or tournament participant's performance. The result is in sharp contrast to the common concerns about doping. Rational participants in tournaments will use such inputs up to the point where their own marginal cost of this input equals their marginal expected benefit in the contest, but if the tournament is appropriately designed, this will not harm society, but can just maximize social welfare.

Next I consider free entry but let be $Z$ fixed. Let individuals have a choice of whether to participate in the tournament or not. Let the number of potential participants be sufficiently large to never be a binding constraint. Denote $n^{*}$ and $n^{p}$ the equilibrium numbers of participants. Further, let the utility of a non-participant be normalized to zero. Then:

Proposition 3 For free entry of participants $n^{*} \leq n^{p}$ holds. 
Proof. The equilibrium numbers of active participants in the tournament without and with constraints on doping effort are the largest integers $n$ for which

$$
\frac{Z}{n^{*}} \geq A\left(a^{*}\right)+B\left(b^{*}\right) \text { and } \frac{Z}{n^{p}} \geq A\left(a^{p}\right)+B(0),
$$

respectively. Accordingly, the results on efforts in the equilibrium in Proposition 1 imply that the right hand side in the second inequality is smaller than the right hand side in the first inequality, and this implies that $n^{*} \leq n^{p}$ holds.

Proposition 3 suggests that fewer individuals enter a contest in which the drug input is available and can freely be chosen. Intuitively, if this additional input can be used, as has been shown in Proposition 1, this generates at least the same amount of input $a$ and a positive amount of input $b$. Accordingly, the participants' cost of their expected equilibrium output is higher if there is no constraint on drug use. As they all have the same chance of winning the contest in the equilibrium, if there is no constraint on drug use, the number of participants must be smaller to make participation worthwhile. The proposition shows that there is a fundamental trade-off between constraints on the types of tournament effort that is admitted, and the number of tournament participants, if the structure of prizes is exogenously given. A prize of a given size allows for more entry in the tournament if the use of some effort is constrained.

Note that disregarding the indivisibility problem with respect to $n$ the sum of rents is zero in the equilibrium with free entry. This property holds for all choices of $Z$ and whether the use of drugs is allowed or not.

\section{Discussion}

Heterogenous tournaments The previous section considered tournaments with a group of homogenous contestants. If the tournament is used as an optimal labor contract in which the employer cares about effort, as was assumed in the previous section, this homogeneity assumption is mainly a simplification.

Selection tournaments and long term performance effects In some tournaments the aim of the designer of the tournament is not to generate 
much aggregate effort. Instead, the designer may want to identify the contestant who is most suitable for carrying out a particular task. If a contest participant who is more suitable for this task has lower cost of generating the same performance than a less suitable participant, then the tournament could be used for selecting the most suitable person. This has been discussed in the literature on selection tournaments ${ }^{9}$, and may, but need not, change the results on the desirability of the availability of performance enhancing drugs. If such drugs just further upscale the performance of particularly suitable contestants, then they could be desirable. They are less desirable if they scramble the signals that would have been generated in the tournament in the absence of such effort. Hence, whether such effort should be banned or not cannot be decided without a closer look at the functional relationship between types of effort, abilities, and observable output. One particular danger of drug use in the selection tournament context that is absent in the tournament that aims at total output is that the cost of drug use may show up with some time delay and may affect later performance. For instance, suppose that some current drug use increases the performance of a contestant in the selection stage, but years after the drug has been used reduces the ability or productivity that is important in the task for which the selection tournament selects the person. In this case, the availability of the drug may destroy the positive correlation between performance in the contest and performance in the later task. If it does the drug reduces or eliminates the use of the tournament as a selection device and a ban of drug use could be useful.

Sports The use of performance enhancing drugs in sports has typically been considered a problem. Few people argue that 'doping' as the use of such drugs is called in sports, should be legalized. ${ }^{10}$ It is no coincidence that the few economic research papers which consider doping in sports contests start with the implicit assumption that doping should be banned, and ask what the optimal design of a mechanism to achieve such a ban is. If sports contests were designed so as to maximize aggregate performance or output, the analysis in section 2 would apply. However, there are a few additional

\footnotetext{
${ }^{9}$ See, e.g., Rosen (1986), Meyer (1991) and Hvide (2003).

${ }^{10}$ Bruno Frey (Neue Züricher Zeitung am Sonntag, 5.10.2003, p.22) is one of the exceptions. He argues that doping should remain banned among amateurs, but should be fully legal among professionals of age 21 and older.
} 
issues in sports contests. First, doping often takes place when athletes are minors. Second, the objective function of organizers of sports tournaments is not to maximize the sum of contestants' output. For instance, issues such as closeness of the competition, fairness, or elegance matter (for a discussion see Hoehn and Szymanski 1999). Third, the precise rules of many sports disciplines about what is allowed, and what not, suggest that the choice of constraints matters for how valuable the performance of athletes is. Performance for given constraints matters, not absolute performance. In Formula I races, for instance, there are clear limits on what teams are allowed to do in order to enhance their performance. Without these constraints, Formula I racing cars could be more powerful and weigh less, teams could be faster etc. but at least the organizers think that the whole enterprise of Formula I racing sports would be less attractive and less valuable. Doping in sports probably must be seen along some of these lines, making a decision about whether doping in sports should be banned less straightforward than in a tournament that aims at maximizing aggregate output net of effort cost.

\section{Conclusions}

In this paper I consider the role of drugs which enhance cognitive abilities for tournaments as optimal labor contracts. It turns out that the availability of such drugs reduces the individual benefit of participating in a tournament for a given number of participants and for a given prize. If the prize is chosen optimally, the availability of such drugs increases the aggregate rent, and hence, increases social welfare. Tournaments with free entry are also

considered. For a given size of the tournament prize, the availability of drugs will generally reduce the number of participants in a tournament if there is free entry, but will increase the output produced by each participant.

\section{References}

Auriol, Emmanuelle, Guido Friebel and Lambros Pechlivanos, 2002, Concerns in teams, Journal of Labor Economics, 20(2), 289-307

Berentsen, Aleksander, 2002, The economics of doping, European Journal of Political Economy, 18, 109-127.

Butcher, James, 2003, Cognitive enhancement raises ethical concerns, 
Academics urge pre-emptive debate on neurotechnologies, Lancet, 362 (July 12), 132-133.

Chen, Kong-Pin, 2003, Sabotage in promotion tournaments, Journal of Law, Economics, and Organization, 19(1), 119-140.

Eber, Nicolas, and Jacques Thépot, 1999, Doping in sport and competition design, Recherches Economiques de Louvain, 65, 435-446.

Epstein, Gil S., and Carsten Hefeker, 2003, Lobbying contests with alternative instruments, Economics of Governance, 4(1), 81-89.

Eyster, Erik, and Matthew Rabin, 2003, Cursed equilibrium, mimeo.

Green, Jerry R., and Nancy L. Stokey, 1983, A comparison of tournaments and contracts, Journal of Political Economy, 91(3), 349-364.

Hoehn, Thomas, and Stefan Szymanski, 1999, The Americanization of European football, Economic Policy, 28, 205-240.

Hvide, Hans K., 2002, Tournament rewards and risk taking, Journal of Labor Economics, 20(4), 877-98

Hvide, Hans K., 2003, Risk taking in selection contests, Games and Economic Behavior, 42(1), 172-179.

Kräkel, Matthias, 2000, Relative deprivation in rank-order tournaments, Labor Economics, 7(4), 385-407.

Kräkel, Matthias, and Dirk Sliwka, 2003, Risk taking in asymmetric tournaments, manuscript, University of Bonn.

Lazear, Edward P., 1989, Pay equality and industrial politics, Journal of Political Economy, 97(3), 561-580.

Lazear, Edward P., 1995, Personel Economics, MIT Press, Cambridge.

Lazear, Edward P. and Sherwin Rosen, 1981, Rank-order tournaments as optimum labor contracts, Journal of Political Economy, 89, 841-864.

Miron, Jeffrey A. and Jeffrey Zwiebel, 1995, The economic case against drug prohibition, Journal of Economic Perspectives, 9(4), 175-192.

Maennig, Wolfgang, 2002, On the economics of doping and corruption in international sports, Journal of Sports Economics, 3(1), 61-89.

Meyer, Margaret A., 1991, Learning from coarse information: biased contests and career profiles, Review of Economic Studies, 58, 15-41.

Robbins, Trevor W., Mitul A. Metha and Barbara J. Sahakian, 2000, Boosting working memory, Science, 290, 2275-2276.

Rosen, Sherwin, 1986, Prizes and incentives in elimination tournaments, American Economic Review, 76(4), 701-715. 